\title{
Genetic adaptation to metal stress by natural populations of Daphnia longispina
}

\author{
Isabel Lopes ${ }^{\mathrm{a}}$, Donald J. Baird ${ }^{\mathrm{b}}$, Rui Ribeiro ${ }^{\mathrm{a}, *}$ \\ ${ }^{a}$ Instituto do Ambiente e Vida, Departamento de Zoologia da Universidade de Coimbra, Largo Marquês de Pombal, 3004-517 Coimbra, Portugal \\ ${ }^{\mathrm{b}}$ Department of Biology, Canadian River Institute, University of New Brunswick, 10 Bailey Drive, P.O. Box 45111, Fredericton, NB Canada E3B 6E1
}

Received 1 April 2004; received in revised form 27 December 2004; accepted 28 December 2004

Available online 23 February 2005

\begin{abstract}
Loss of genetic diversity in natural populations as a result of chemical contamination has been reported in some studies. Here, four field populations of Daphnia longispina, two from sites historically impacted by acid mine drainage (AMD) and two from reference sites, were used to address four objectives: (1) identify differences in sensitivity between the stressed and reference populations; (2) distinguish between the components responsible for those differences (environmental influence vs genetic determination); (3) determine if genetically determined responses of reference and stressed populations converge from lethal to sublethal levels of contamination; and (4) evaluate losses of variability in genetically determined resistance by the stressed populations. Lethal and sublethal assays were carried out by exposing nonacclimated and acclimated neonates to AMDcontaminated waters and to copper dissolved in an artificial medium. Results indicate that both nonacclimated and acclimated individuals from the stressed populations are significantly less sensitive to AMD-contaminated waters than those from the reference populations, at both lethal and sublethal levels. The hypothesis of a convergence from lethal to sublethal responses was confirmed. (C) 2005 Elsevier Inc. All rights reserved.
\end{abstract}

Keywords: resistance; adaptation; metals; acid mine drainage; Daphnia longispina

\section{Introduction}

Predicting how natural communities respond to contamination is an important aim of ecotoxicology bioassays. Such bioassays are usually carried out using groups of standard organisms cultured and tested under controlled conditions, thus minimizing the influence of genetic and environmental factors on the measured effects. However, extrapolation from laboratory results to field responses requires the understanding of how such factors can affect the response of natural populations. Many studies have reported differences in sensitivity to contamination between clones or populations of the same species, namely, in cladocerans (Grothe and Kimerle, 1985; Baird et al., 1990a, b,

\footnotetext{
${ }^{*}$ Corresponding author. Fax: +351239824226.

E-mail address: rui.ribeiro@zoo.uc.pt (R. Ribeiro).
}

1991; Soares et al., 1992; Reinikainen et al., 1998), amphipods (Howell, 1985; France, 1987; Maltby and Crane, 1994), isopods (Brown, 1978; Maltby et al., 1987), and gastropods (Lam and Calow, 1989; Forbes et al., 1995; Lam, 1996). At the population level, three scenarios could explain an increased average tolerance to contamination: (1) the occurrence of environmentally induced physiological alterations in the individuals, which would not yield to shifts in the genetic structure of the population; (2) the elimination of sensitive individuals, which would reduce the genetic variability of the population through genetic erosion; and (3) the appearance and spread of a new gene or a new combination of genes underlying a new or a more efficient resistance mechanism, which would enlarge the amplitude of responses through the appearance of new genotypes. The latter two scenarios involve changes in the gene frequencies in the population, i.e., 
a microevolution process. Furthermore, and according to the convergence hypothesis, genetically determined variability tends to converge from lethal to sublethal responses, i.e., from strongly to moderately toxic levels of contamination. This follows, because at high contaminant concentrations lethal responses are likely to involve fewer and more specific mechanisms (e.g., inhibition of a particular enzyme, metallothionein detoxification) (Posthuma and van Straalen, 1993; Taylor and Feyereisen, 1996) than sublethal responses to low concentrations, where many genes may regulate complex general responses closely linked to fitness, such as behavioral and energy allocation shifts (Bradley et al., 1991; Allen et al., 1995). Thus, genetic variation in sublethal responses, which is under continuous directional selection, is expected to be lower than for lethal responses, where the selection regime may only act intermittently across generations.

The main objectives of this study were: (1) to quantify differences in sensitivity to chemical stress between populations living in reference and historically contaminated sites; (2) to determine if those differences were due to acclimatization and/or microevolutionary phenomena; (3) to determine if genetically determined resistance by reference and stressed populations converges from lethal to sublethal levels of contamination; and (4) to evaluate the genetic erosion in stressed populations, i.e., the amplitude decrease in the variability of genetically determined resistance.

Field populations of the cladoceran Daphnia longispina stressed by acid mine drainage (AMD) were selected to carry out this study. Daphnids are ideal organisms to study acclimatization versus genetically determined responses as they exhibit facultative asexual reproduction by ameiotic parthenogenesis. Two reference and two historically stressed populations were sampled and studied.

Several studies have reported the development of tolerance to heavy metals by aquatic organisms, namely, bacteria (Pickaver and Lyes, 1981; Honor and Hilt, 1985; Nies and Silver, 1995), algae (Kuwabara and Leland, 1986), annelids (Lucan-Bouché et al., 1999), mollusks (Lam, 1996), crustaceans (LeBlanc, 1982; Stuhlbacher and Maltby, 1992; Stuhlbacher et al., 1993; Maltby and Crane, 1994), and insects (Groenendijk et al., 1999). Specifically for cladocerans, acclimatization phenomena were investigated by Bodar et al. (1990), who exposed three generations of lab-cultured D. magna to cadmium and observed that organisms developed tolerance to toxic sublethal effects of cadmium, which disappeared within 21 days of return to uncontaminated conditions.

Two experimental phases were carried out to address the four objectives defined above. First, the comparison of sensitivity between reference and historically stressed populations to AMD contamination was accomplished with nonacclimated neonates from recently field-collected egg-bearing females. Second, maternal and environmental influences were controlled and the genetic determination of resistance differences was evaluated by exposing laboratory-acclimated individuals to different levels of lethal and sublethal toxicant concentrations.

\section{Materials and methods}

\subsection{Study site}

An aquatic system impacted with AMD, from an abandoned copper mine (active from 1868 to 1967), was selected for the development of this study. Though ore exploitation ended more than 30 years ago, continuous oxidation of abandoned mine tailings still produces a highly acidic effluent, contaminated with heavy metals (Fe, Al, $\mathrm{Zn}, \mathrm{Cu}, \mathrm{Mn}, \mathrm{Co}, \mathrm{Ni}, \mathrm{Cd}, \mathrm{Pb}, \mathrm{Cr}, \mathrm{As}$, in decreasing order) (Table 1). This untreated effluent currently discharges into the Chança River Reservoir within the Guadiana River Basin (Fig. 1) (Pereira et al., 1995, 1999, 2000; Ribeiro et al., 1995; Lopes et al., 1999a). For those water samples that exerted toxic effects (V1, V2, and T6; see below), data on 12 metals, measured by atomic absorbance spectroscopy, from previously collected samples with almost matching conductivity values are presented in Table 1. Further metal analyses were considered unnecessary as no concentration-effect relationships were intended to be established, but solely the comparison of relative sensitivities between populations.

This aquatic system is highly suited for the study of adaptations occurring in natural populations exposed to

Table 1

Alkalinity $\left(\mathrm{mg} \mathrm{CaCO}_{3} / \mathrm{L}\right)$ and concentrations $(\mathrm{mg} / \mathrm{L})$ of metals (total recoverable) from previously collected water samples with conductivity values $(\mu \mathrm{S} / \mathrm{cm})$ close to those of samples that exerted toxic effects in the present study (V1-V4 and T6)

\begin{tabular}{lcc}
\hline & $\mathrm{V} 1-\mathrm{V} 4$ & $\mathrm{~T} 6$ \\
\hline Conductivity & $290-299$ & 190 \\
Previous conductivity & 312 & 271 \\
Previous alkalinity & 6.5 & 27.0 \\
$\mathrm{Al}$ & 11.3 & $<0.1$ \\
$\mathrm{As}$ & $<0.005$ & $<0.005$ \\
$\mathrm{Cd}$ & 0.0286 & 0.00082 \\
$\mathrm{Cr}$ & $<0.015$ & $<0.015$ \\
$\mathrm{Cu}$ & 1.7 & 0.027 \\
$\mathrm{Fe}$ & 1.64 & 0.129 \\
$\mathrm{Mn}$ & 3.07 & 0.081 \\
$\mathrm{Ni}$ & 68.0 & $<0.03$ \\
$\mathrm{~Pb}$ & 4.60 & 0.640 \\
$\mathrm{Hg}$ & $<0.0002$ & $<0.0002$ \\
$\mathrm{Co}$ & 90.0 & $<0.03$ \\
$\mathrm{Zn}$ & 12.10 & 0.288 \\
\hline
\end{tabular}




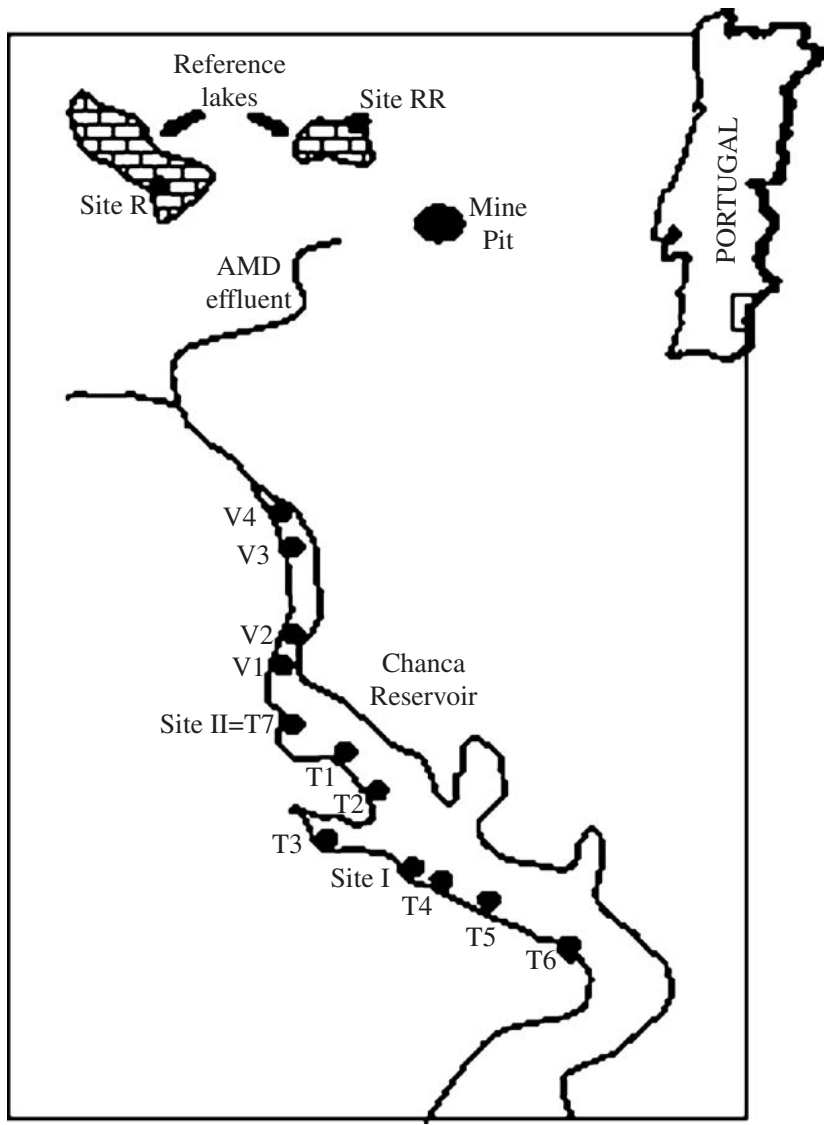

Fig. 1. Scheme of the Chança reservoir with the localization of sites where organisms and water were sampled.

historical chemical stress, for three reasons: (1) The source of contamination is isolated and identified $(\mathrm{pH}$ and, mainly, heavy metals); no agriculture or industrial activities are present and there is no urban runoff. (2) Reference sites free of metal mining contamination exist close to the contaminated area. (3) Extensive data on the biology, ecology, and water chemistry of the system are available (Pereira et al., 1995, 1999, 2000; Ribeiro et al., 1995; Lopes et al., 1999a, b).

\subsection{Field populations}

Daphnia longispina O.F. Müller were collected from two reference lakes (Ref1: $\mathrm{pH} 7.5,189 \mu \mathrm{S} / \mathrm{cm}$, dissolved oxygen (DO) $8.7 \mathrm{mg} / \mathrm{L}$; and Ref2: $\mathrm{pH} 7.61,193 \mu \mathrm{S} / \mathrm{cm}$, DO $9.3 \mathrm{mg} / \mathrm{L}$, located upstream from the contaminated area) and two contaminated sites (Cont1: $\mathrm{pH}$ 7.1, $209 \mu \mathrm{S} / \mathrm{cm}$, DO $9.1 \mathrm{mg} / \mathrm{L}$; and Cont2: pH 7.0, $231 \mu \mathrm{S} /$ $\mathrm{cm}$, DO $9.4 \mathrm{mg} / \mathrm{L}$, located along the contamination gradient, Cont 2 being more impacted than Cont 1 ) (Fig. 1).

The collection of daphnids followed the procedure described by Lopes et al. (1999b). Individuals were taken to the laboratory, and, by use of a dissecting microscope, egg-bearing females were transferred to culture beakers filled with $50-\mu \mathrm{m}$-filtered site water. Neonates born the day after collection, from fieldcollected females, were used to perform toxicity assays (nonacclimated individuals). The remaining neonates were maintained in the laboratory and acclimated to controlled conditions: $25 \pm 1{ }^{\circ} \mathrm{C}$ with a photoperiod of 14:10 h L:D in American Society for Testing and Materials (ASTM) hardwater medium (ASTM, 2000), with vitamins and the organic additive Marinure 25 (Baird et al., 1989), and fed daily with the green algae Pseudokirchneriella subcapitata (Koršhikov) Hindak (formerly known as Selenastrum capricornutum Printz) $\left(3 \times 10^{5}\right.$ cells $/ \mathrm{mL} /$ day $)$.

Conductivity (WTW LF92, Brussels, Belgium), pH (WTW 537), and DO (WTW OXI 92) were measured at each sampling site and at the beginning and at the end of each assay.

\subsection{Toxicity assays}

Lethal and sublethal toxicity assays were performed with neonates from the four $D$. longispina populations under controlled conditions of temperature $\left(25 \pm 1{ }^{\circ} \mathrm{C}\right)$ and photoperiod (14:10 h L:D). Assays were conducted with acclimated (after at least five generations under laboratory conditions) neonates $(6-24 \mathrm{~h}$ old), from the third and fourth broods and with nonacclimated neonates, 6-14h old, from recently field-collected eggbearing females (Weber, 1991). In lethal assays no food was added, while in sublethal assays individuals were fed daily with $P$. subcapitata $\left(3 \times 10^{5}\right.$ Cells $/ \mathrm{mL} /$ day which corresponds to $1.2 \times 10^{7}$ cells/individual), water being renewed every other day.

Individuals were exposed to water samples (filtered through a $50-\mu \mathrm{m}$ mesh) with different degrees of toxicity (this classification was based on the extent of observed effects):

\section{Very toxic waters (V1 to V4)}

Lethal toxicity assays (cumulative mortality) were performed with the four populations by exposing nonacclimated and acclimated neonates to strongly AMD-impacted water samples (V1 to V4). Five individuals were introduced simultaneously in $42-\mathrm{mL}$ glass vessels filled with $30 \mathrm{~mL}$ of water sample, with four replicates per treatment. Immobilization was checked continuously during the first $15 \mathrm{~min}$, every $3 \mathrm{~min}$ from 15 to $30 \mathrm{~min}$, every $5 \mathrm{~min}$ from 30 to $120 \mathrm{~min}$, every $15 \mathrm{~min}$ from 2 to $6 \mathrm{~h}$, every hour from 6 to $12 \mathrm{~h}$, and at 18, 24, 36, and $48 \mathrm{~h}$ (Lopes et al., 1999a, 2000; Ribeiro et al., 2000). An assay ended when all the daphnids died or after $168 \mathrm{~h}$ of exposure if at least one individual survived for that period. 


\section{Moderately toxic waters ( $T 7$ and T6)}

Sublethal toxicity assays were performed with the four populations by exposing neonates to moderately AMD-impacted waters (T7 and T6, T7 being the natural water from where the population Cont 2 was collected). First, nonacclimated neonates were exposed to the AMD-impacted water sample T7 to compare reproduction between the four populations. Acclimated individuals were also exposed to AMD-impacted waters and to three copper concentrations $(15,30$, and $60 \mu \mathrm{g} / \mathrm{L}$ of $\mathrm{Cu}$ ), added as copper sulfate (supplied by Merck, Darmstadt, Germany), dissolved in nanopure water $(80 \mathrm{mg} / \mathrm{L})$ with a magnetic stirrer and then diluted with ASTM. Each individual was introduced in a $42-\mathrm{mL}$ glass vessel filled with $40 \mathrm{~mL}$ of water sample. For each treatment 12 replicates were used. Body length (only for acclimated individuals) and reproduction (number of neonates per female) were recorded. Sublethal assays ended when all daphnids released their fourth brood.

Table 2 records the $\mathrm{pH}$, conductivity, and $\mathrm{DO}$ of the waters used in the toxicity assays: $\mathrm{pH}$ ranged from 5.9 to 7.5 , conductivity from 190 to $299 \mu \mathrm{S} / \mathrm{cm}$, and DO from 8.3 to $10.3 \mathrm{mg} / \mathrm{L}$. These parameters exhibited very low variation during toxicity assays. Highest variations registered for $\mathrm{pH}$, conductivity, and $\mathrm{DO}$ were 0.1 , $3 \mu \mathrm{S} / \mathrm{cm}$ and $0.2 \mathrm{mg} / \mathrm{L}$, respectively.

\subsection{Data analysis}

Survivorship curves from cumulative mortality assays were analyzed with the Gehan-Wilcoxon $\chi^{2}$ test (Pyke and Thompson, 1986), and when two samples were to be compared, the Fisher exact test was used (Zar, 1996). Median lethal time values and respective $95 \%$ confidence limits were calculated using probit analysis (Sparks, 2000). Body length and reproduction were analyzed by ANOVA, with post hoc comparisons using the Tukey HSD test (Zar, 1996). Whenever heteroscedasticity or nonnormality of data was pronounced, a nonparametric analysis of variance was employed (Kruskal-Wallis) followed by the nonparametric multiple comparison test (Zar, 1996). Homogeneity between coefficients of variation was analyzed using the Miller and Feltz equation (Zar, 1996). Median lethal time values were calculated using the program Probit Analysis 2.2 (developed by A. Nogueira, Coimbra,
Portugal, unpublished). All other statistics, except CV comparisons, were performed using the program Statistica for Windows 4.3 (StatSoft, Aurora, CO, USA).

\section{Results}

\subsection{Tolerance of reference versus stressed populations}

In the first experimental phase, nonacclimated neonates, from recently field-collected females, were exposed to very and moderately toxic water samples with the aim of detecting differences in sensitivity between reference and historically stressed field populations. Assays performed with nonacclimated individuals under starvation revealed that population Contl was significantly more resistant to AMD contamination than populations Ref1 and Ref2, when exposed to water sample V1 (Gehan-Wilcoxon test: $P<10^{-5}$, $\chi^{2}(3)=94.8$ ) (Fig. 2). After $168 \mathrm{~h}$ of exposure to the contaminated water, all individuals from populations Ref 1 and Ref 2 died, while only $40 \%$ died in population Cont1. Some of the mortality registered in Ref1 could be due to a higher sensitivity to starvation (6 days). Survival above $80 \%$ was observed when individuals from populations Ref1, Ref2, and Cont1 were exposed to the water samples from which each was collected.

At sublethal levels of AMD contamination, with food added, it was found that the reproductive output of the most stressed population (Cont2) was significantly lower than that of other populations, when exposed to their natural waters (one-way ANOVA: $P<10^{-4}, F(3,36)=$ 10.2) (Fig. 3). Water sample $T 7$, which was the natural water of population Cont2, was toxic to all other populations as reproduction of Ref1, Ref2, and Cont1 exposed to T7 was significantly lower than reproduction of these populations when exposed to their natural waters ( $t$ tests: $\left.P<10^{-3}, t(18) \geqslant 3.97\right)$. No significant differences were found between the four populations exposed to T7 (one-way ANOVA: $P=0.452$, $F(3,36)=0.90)($ Fig. 3).

When analyzing the variability in reproductive responses between individuals exposed to their natural water and to $\mathrm{T} 7$ water, significant changes were observed (Miller and Feltz tests: $P<0.01, F(1)>7.30$ ); in populations Ref1 and Cont 1 the coefficient of

Table 2

Conductivity $(\mu \mathrm{S} / \mathrm{cm}), \mathrm{pH}$, and dissolved oxygen $(\mathrm{DO}, \mathrm{mg} / \mathrm{L})$ values of water samples from the S. Domingos abandoned mine (Southeast Portugal) used in toxicity assays

\begin{tabular}{lcccccccrrrrr}
\hline & $\mathrm{V} 1$ & $\mathrm{~V} 4$ & $\mathrm{~V} 3$ & $\mathrm{~V} 2$ & $\mathrm{~T} 7$ & $\mathrm{~T} 1$ & $\mathrm{~T} 2$ & $\mathrm{~T} 3$ & $\mathrm{~T} 4$ & $\mathrm{~T} 5$ & $\mathrm{~T} 6$ \\
\hline Conductivity & 293 & 299 & 295 & 290 & 231 & 190 & 198 & 213 & 202 & 218 & 190 \\
pH & 7.0 & 7.0 & 5.9 & 6.1 & 7.0 & 6.8 & 6.6 & 6.6 & 7.5 & 7.2 & 6.2 \\
DO & 8.7 & 9.1 & 8.5 & 8.3 & 9.6 & 10.1 & 9.2 & 9.0 & 8.9 & 10.3 & 9.7 \\
\hline
\end{tabular}




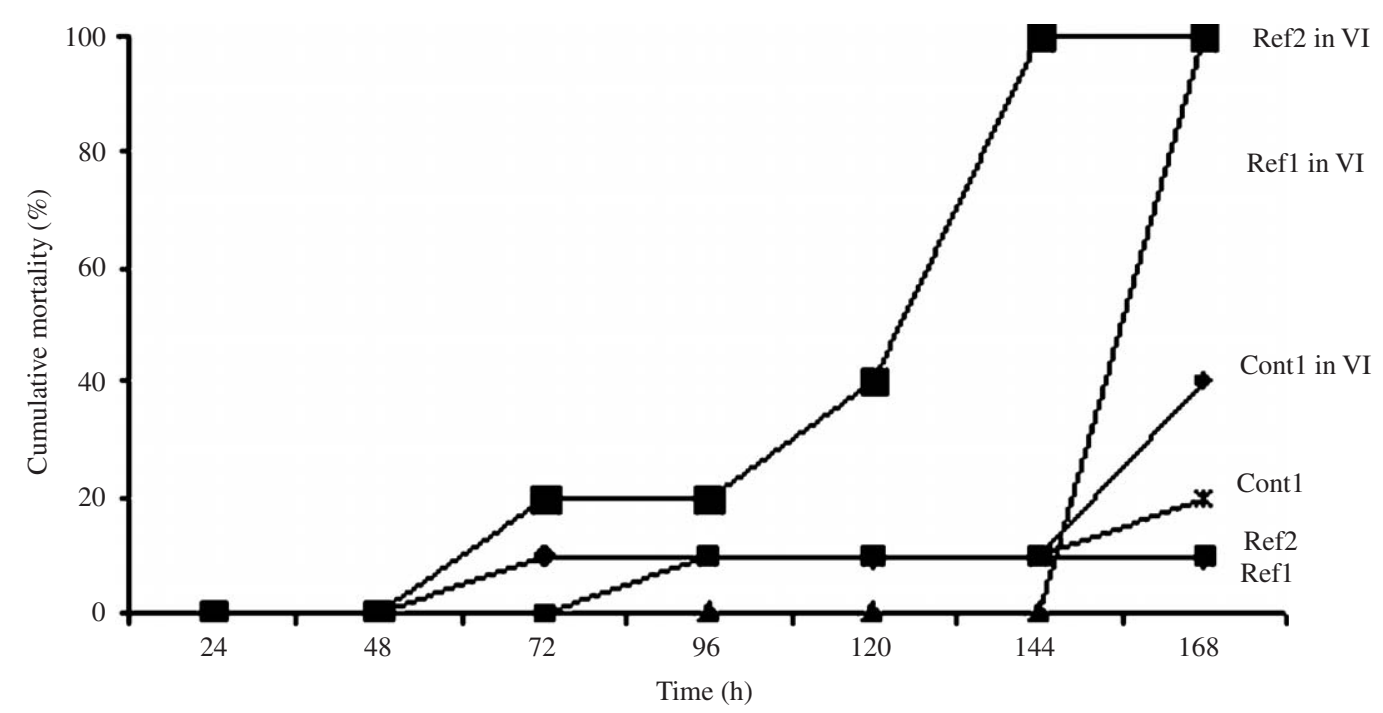

Fig. 2. Cumulative mortality (\%) of nonacclimated Daphnia longispina neonates from reference (Ref1 and Ref2) and historically stressed (Cont1) populations exposed to their natural waters (Cont1, Ref1, and Ref2) and to water sample V1 (Cont1 in V1, Ref1 in V1, and Ref2 in V1).

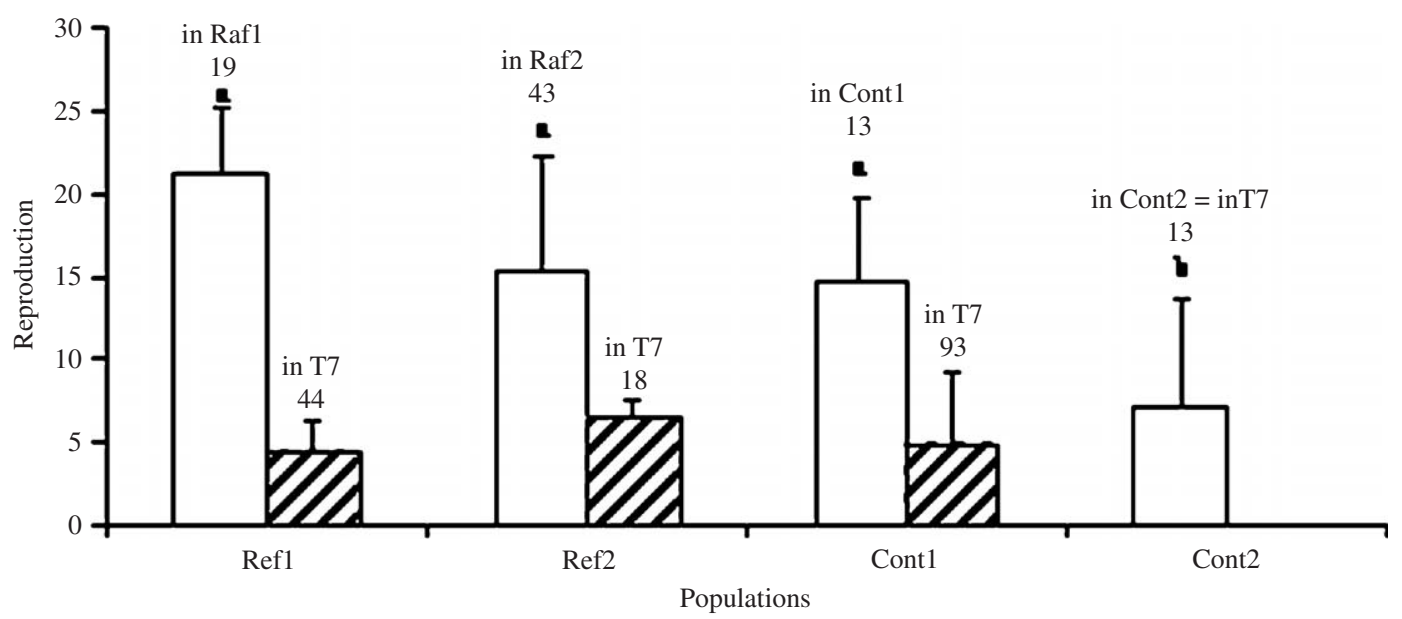

Fig. 3. Reproduction (number of juveniles per female) (average + SD) of nonacclimated Daphnia longispina from reference (Ref1 and Ref2) and historically stressed (Cont1 and Cont2) populations exposed to their natural waters (white bars) and to T7 water, which was sampled where population Cont 2 was collected (striped bars). Coefficients of variation (\%) are presented.

variation increased and in population Ref2 it decreased (Fig. 3). Comparing variability in responses between populations exposed to their natural waters, population Cont2 presented a significantly higher variability (Miller and Feltz test: $\left.P \leqslant 0.001, \chi^{2}(3)=16.8\right)$.

\subsection{Environmental influence versus genetic determination}

In the second experimental phase, all four populations were acclimated to controlled conditions and exposed to very and moderately toxic waters. This phase aimed to evaluate the degree of genetic determination in resistance differences between reference and stressed populations, and to test the hypothesis that variability in response between those populations would converge from high to low levels of contamination.

Individuals from reference populations (Ref1 and Ref2) exhibited poor survival compared with those from populations Cont 1 and Cont 2 when exposed to the very toxic water samples V4, V3, and V2 (Gehan-Wilcoxon tests: $P<10^{-5}, \chi^{2}(2) \geqslant 37.5$, for all water samples tested) (Fig. 4). No significant differences were observed within the reference populations (Ref1 and Ref2) and within stressed populations (Cont1 and Cont2), in any of the tested waters (six Fisher exact tests: $P>0.05$ ). Median lethal time values (and respective 95\% confidence limits) for populations Ref1, Ref2, Cont1, and Cont2 in the water sample V4 were 1.51 (1.08-2.12), 2.00 (1.67-2.35), $27.2(15.0-46.5)$, and $57.2(34.8-95.7)$ h, respectively. 

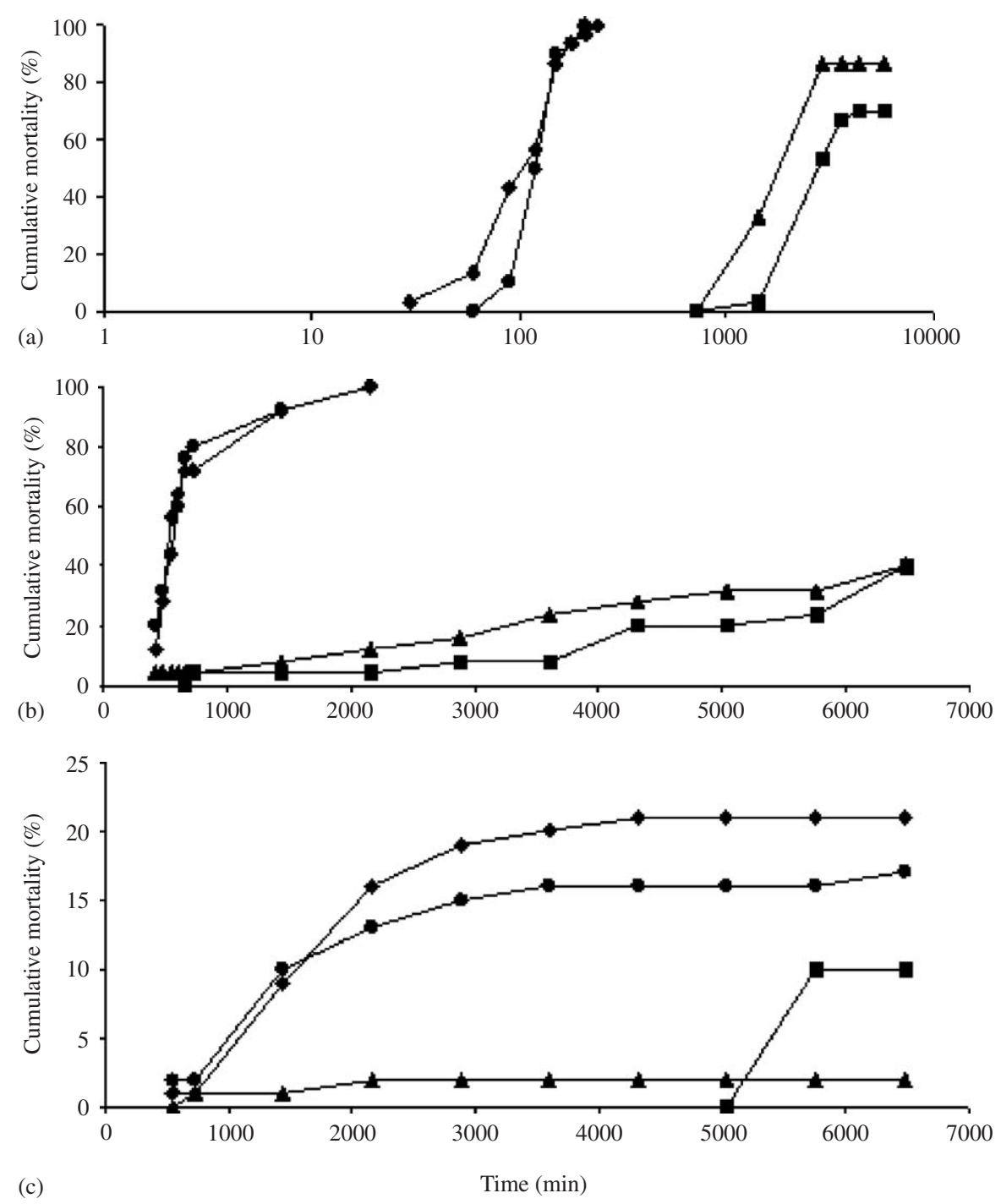

Fig. 4. Cumulative mortality (\%) of acclimated Daphnia longispina neonates from reference (Ref1, $\bullet$ and Ref2, $\bullet$ ) and historically stressed (Cont1, $\boldsymbol{\Delta} ;$ and Cont2, $\mathbf{\square}$ ) populations exposed to V4 (A), V3 (B), and V2 (C) water samples.

No significant differences in reproduction were detected among the four populations, after acclimation, in the ASTM medium or when exposed to moderately toxic water samples $\mathrm{T} 1$ and T2 (Fig. 5A, Table 3), neither being toxic to individuals from any of the four populations (Fig. 5A, Table 4). The variability in responses observed in ASTM were significantly lower in population Cont 1 relative to the other three (Miller and Feltz test: $\left.P<0.025, \chi^{2}(3)=9.60\right)$. Within populations, significant differences in coefficients of variation were observed only for population Cont1 (Miller and Feltz test: $\left.P<0.005, \chi^{2}(2)=14.9\right)$.

Similarly, a subsequent identical assay, with water samples T3 to T5, revealed no significant differences between populations (Fig. 5B, Table 3) or between AMD waters and the respective control (Fig. 5B, Table 4). Once again, no differences in reproduction were found between the controls of the four populations (Table 4). Contrary to the previous assay, no significant differences were observed between the coefficients of variation of the four populations exposed to ASTM. Significant differences in variability within populations were registered for populations Ref1, Cont1, and Cont2 (Miller and Feltz tests: $P<0.005, \chi^{2}(3)=22.0,14.5$, and 17.1, respectively).

In another assay, water sample $\mathrm{T} 6$ presented toxicity to the acclimated individuals from populations Cont2, Ref1, and Ref2 ( $t$ tests: $P<10^{-2}, t(22)<5.10$ ) (Fig. 6), though no differences were observed in the reproduction of population Cont 1 when exposed to the control and to the T6 sample ( $t$ test: $P=0.607, t(22)=3.65)$. No significant differences were detected between controls (Table 4). Significant differences in the relative variability to the mean were detected between populations 

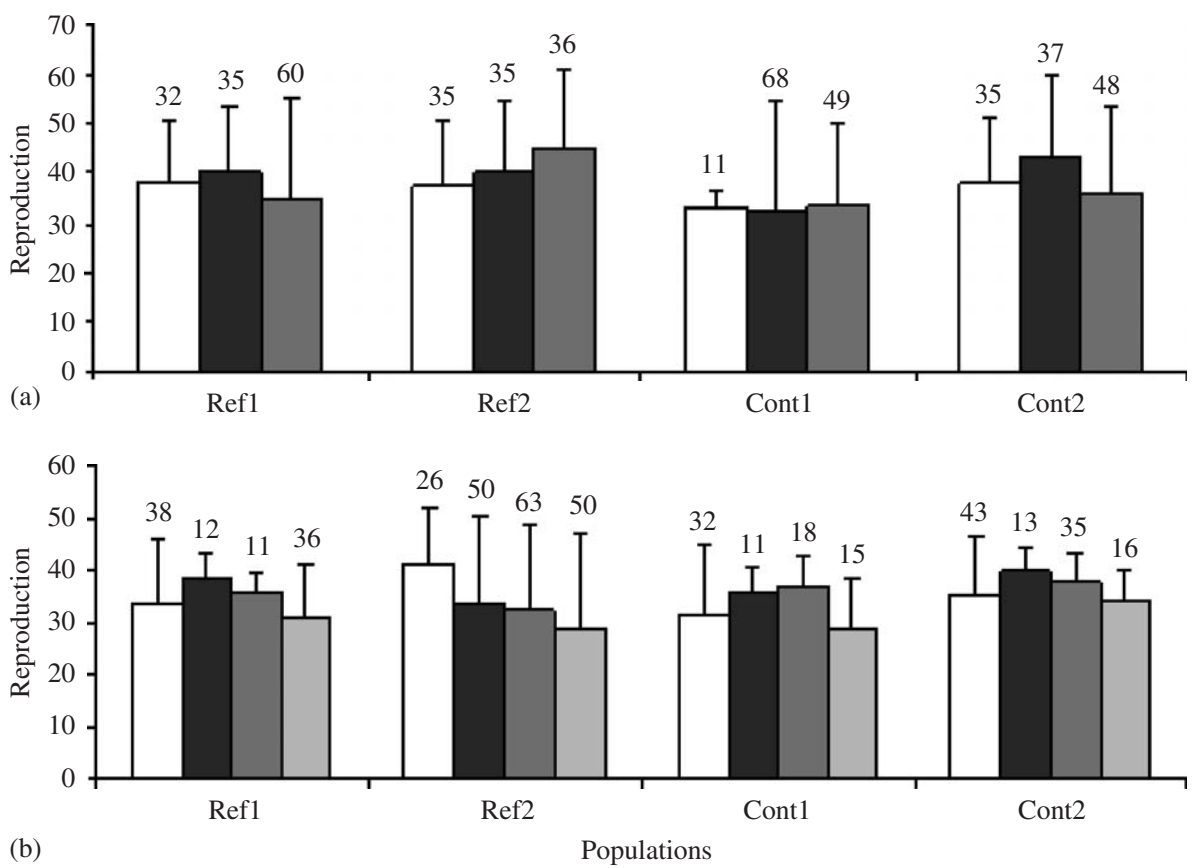

Fig. 5. Reproduction (number of juveniles per female) (average $+\mathrm{SD}$ ) of acclimated Daphnia longispina from reference (Ref1 and Ref2) and historically stressed (Cont1 and Cont2) populations exposed to T1 and T2 (A-heavy and light grey, respectively) and to T3, T4, and T5 (B-heavy, medium, and light grey, respectively) water samples. In both (A) and (B) white bars represent ASTM hardwater. Coefficients of variation (\%) are presented.

Table 3

Two-way ANOVA analysis for reproduction of females from Ref1, Ref2, Cont1, and Cont2 populations exposed to several AMDcontaminated waters and three copper concentrations $(15,30$, and $60 \mu \mathrm{g} / \mathrm{L})$

\begin{tabular}{lrrc}
\hline Source & $d f$ & MS & \multicolumn{1}{c}{$F$} \\
\hline Reproduction (T1 and T2 waters) & & & \\
$\quad$ Populations & 3 & 429 & $1.8 \mathrm{~ns}^{\mathrm{a}}$ \\
$\quad$ Waters & 2 & 78 & $0.3 \mathrm{~ns}$ \\
$\quad$ Populations $\times$ waters & 6 & 122 & $0.5 \mathrm{~ns}$ \\
$\quad$ Error & & 243 & \\
Reproduction (T3-T5 waters) & 3 & 107 & $0.9 \mathrm{~ns}$ \\
$\quad$ Populations & 3 & 383 & $3.3^{*}$ \\
$\quad$ Waters & 9 & 114 & $1.0 \mathrm{~ns}$ \\
$\quad$ Populations $\times$ waters & 176 & 117 & \\
Error & & & \\
Reproduction (copper) & 2 & 96 & $1.7 \mathrm{~ns}$ \\
$\quad$ Populations & 3 & 767 & $13.7^{* *}$ \\
$\quad$ Waters & 6 & 86 & $1.5 \mathrm{~ns}$ \\
Populations $\times$ waters & 132 & 56 & \\
$\quad$ Error & & & \\
\end{tabular}

${ }^{a}$ ns (nonsignificant), $P>0.05$.

${ }^{*} P \leqslant 0.05$.

$* * P \leqslant 0.0001$.

exposed to ASTM medium (Miller and Feltz test: $\left.P \leqslant 0.001, \chi^{2}(3)=44.0\right)$, populations Ref1 and Cont2 presenting the highest values and the other two populations the lowest values. Nevertheless, on exposure to sample T6, no significant differences were observed among coefficients of variation (Miller and Feltz test: $\left.P>0.90, \chi^{2}(3)=0.694\right)$. Comparing these coefficients, for each population, populations Ref2, Cont1, and Cont 2 presented a significantly higher variability when exposed to T6 water sample than when exposed to ASTM medium (Miller and Feltz tests: $P<0.05, \chi^{2}(3)=4.42,5.79$, and 3.89 , respectively).

Assays performed with copper revealed significant differences in reproduction between concentrations but not between the three tested populations (Table 3) (Fig. 7A). When controls of the three populations were compared, no significant differences were observed (Table 4). Only for population Ref2, the highest copper concentration was toxic to reproduction, with a significant difference from the respective control (Table 4). Significant differences in the body length of control individuals were found between populations, Ref2 individuals being longer than the others (Table 4). When body lengths were compared, only the highest copper concentration $(60 \mu \mathrm{g} / \mathrm{L})$ was toxic to the three populations (Table 4), but the two lowest concentrations also exerted toxic effects on population Ref2 (Table 4) (Fig. 7B). Coefficients of variation presented significant differences when populations exposed to each treatment were compared (control, 15, 30, and $60 \mu \mathrm{g} / \mathrm{L}$ ) (Miller and Feltz tests: $\left.P<0.05, \chi^{2}(2) \geqslant 7.30\right)$, except for body length at $30 \mu \mathrm{g} / \mathrm{L}$ (Miller and Feltz test: $P>0.25$, 
Table 4

One-way ANOVA for reproduction and body length of females from Ref1, Ref2, Cont1, and Cont2 populations exposed to several AMDcontaminated waters and three copper concentrations $(15,30$, and $60 \mu \mathrm{g} / \mathrm{L})$

\begin{tabular}{|c|c|c|c|c|c|}
\hline Source & $d f_{\text {effect }}$ & $d f_{\text {error }}$ & $\mathrm{MS}_{\text {effect }}$ & $\mathrm{MS}_{\text {error }}$ & $F$ \\
\hline \multicolumn{6}{|l|}{ Reproduction ( $\mathrm{T} 1$ and $\mathrm{T} 3$ ) } \\
\hline Waters (Ref1) & 2 & 33 & 92 & 256 & $0.4 \mathrm{~ns}^{\mathrm{i}}$ \\
\hline Waters (Ref2) & 2 & 33 & 179 & 210 & $0.9 \mathrm{~ns}$ \\
\hline Waters (Cont 1$)$ & 2 & 33 & 3.9 & 258 & $0.02 \mathrm{n}$ \\
\hline Waters (Cont2) & 2 & 33 & 170 & 246 & $0.7 \mathrm{~ns}$ \\
\hline \multicolumn{6}{|l|}{ Reproduction (T3-T6) } \\
\hline Waters (Ref1) & 3 & 44 & 149 & 78 & $1.9 \mathrm{~ns}$ \\
\hline Waters (Ref2) & 3 & 44 & 316 & 250 & $1.3 \mathrm{~ns}$ \\
\hline Waters (Cont 1$)$ & 3 & 44 & 83 & 54 & $1.5 \mathrm{~ns}$ \\
\hline Waters (Cont2) & 3 & 44 & 177 & 85 & $2.1 \mathrm{~ns}$ \\
\hline \multicolumn{6}{|l|}{ Reproduction (T3-T6) } \\
\hline Populations (control waters) & 3 & 79 & 212 & 97 & $2.2 \mathrm{~ns}$ \\
\hline \multicolumn{6}{|l|}{ Reproduction (T6) } \\
\hline Populations & 3 & 44 & 105 & 41 & $2.5 \mathrm{~ns}$ \\
\hline \multicolumn{6}{|l|}{ Reproduction (copper) } \\
\hline Populations (control waters) & 2 & 33 & 20 & 38 & $0.5 \mathrm{~ns}$ \\
\hline \multicolumn{6}{|l|}{ Reproduction (copper) } \\
\hline Concentrations (Ref2) & 3 & 44 & 654 & 85 & $7.7^{*}$ \\
\hline Concentrations (Cont1) & 3 & 44 & 203 & 37 & $5.5 \mathrm{~ns}$ \\
\hline Concentrations (Cont2) & 3 & 44 & 81 & 46 & $1.8 \mathrm{~ns}$ \\
\hline \multicolumn{6}{|l|}{ Body length (copper) } \\
\hline Populations (control waters) & 2 & 32 & 63 & 2.8 & $22.6^{* *}$ \\
\hline \multicolumn{6}{|l|}{ Body length (copper) } \\
\hline Concentrations (Ref2) & 3 & 41 & 208 & 3 & $61.7^{* *}$ \\
\hline Concentrations (Cont 1 ) & 3 & 43 & 58 & 5 & $13.0^{* *}$ \\
\hline Concentrations (Cont2) & 3 & 43 & 46 & 5 & $9.5^{* *}$ \\
\hline
\end{tabular}

${ }^{a}$ ns (nonsignificant), $P>0.05$.

$* P \leqslant 0.05$.

** $P \leqslant 0.001$.

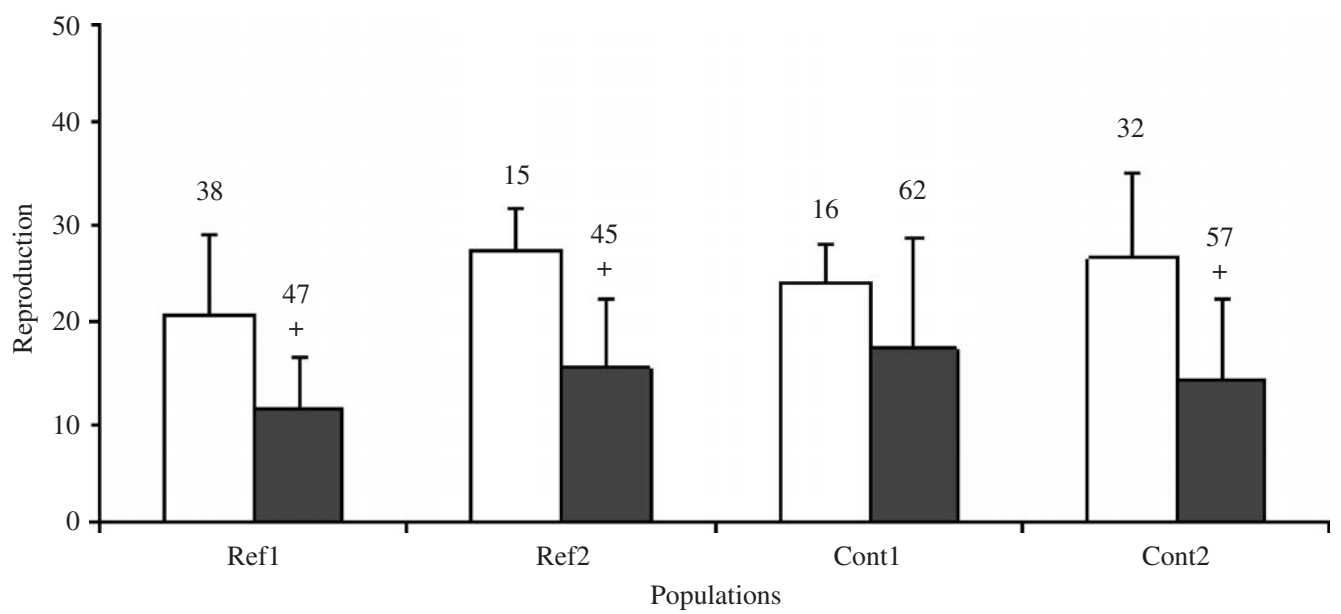

Fig. 6. Reproduction (number of juveniles per female) (average + SD) of acclimated Daphnia longispina from reference (Ref1 and Ref2) and from historically stressed (Cont1 and Cont2) populations exposed to ASTM hardwater (white bars) and to the T6 water sample (grey bars). Coefficients of variation $(\%)$ are presented. "Significant difference $(P \leqslant 0.05)$ relative to the respective control (ASTM hardwater).

$\left.\chi^{2}(2)=4.02\right)$. Within populations, opposite results were observed for fecundity and body length. For the former, significant differences between coefficients of variation were found only in population Ref2 (Miller and Feltz: $P<0.025, \chi^{2}(2)=7.82$ ), whereas in body length, significant differences were present in populations Cont 1 

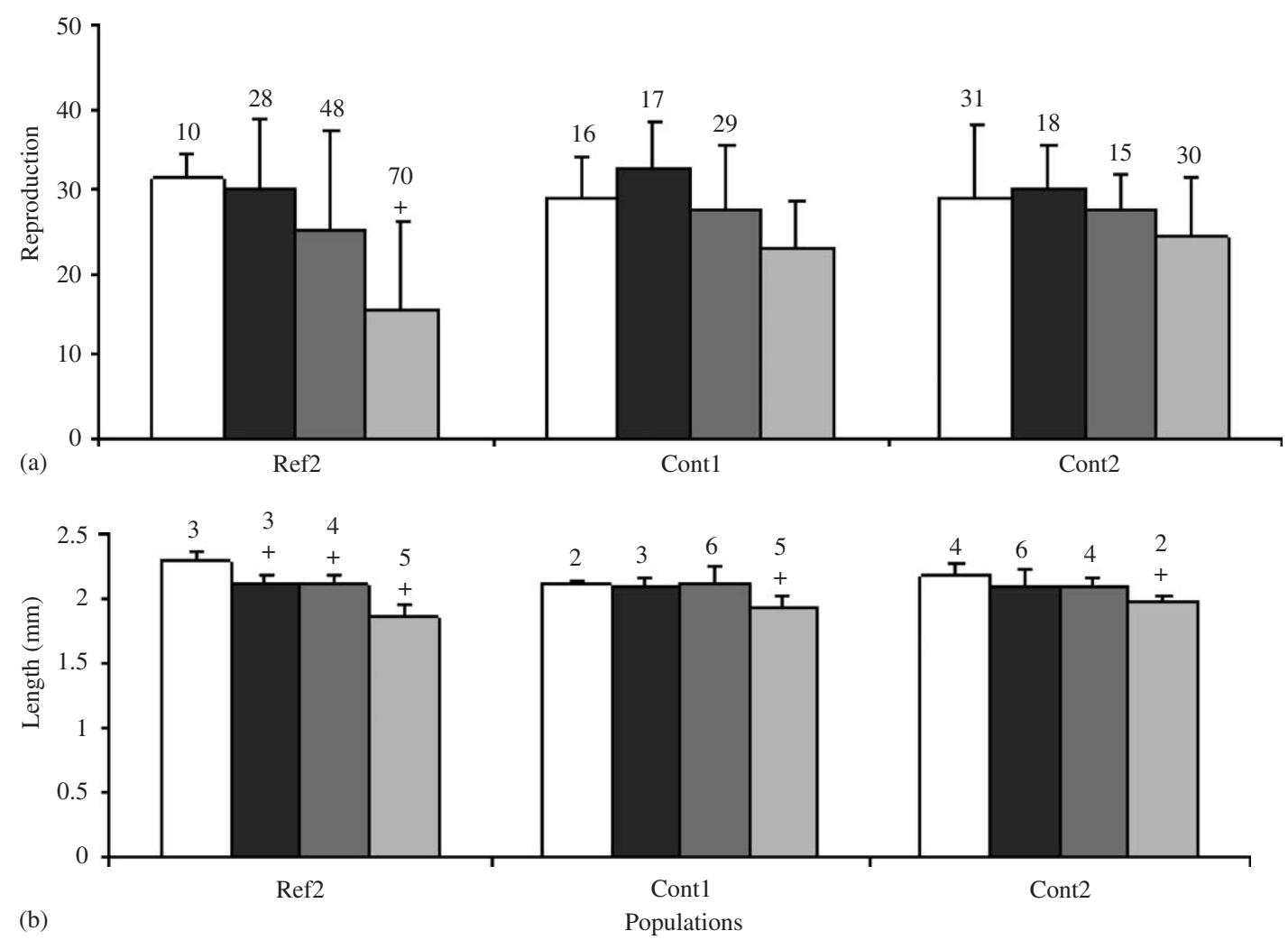

Fig. 7. Reproduction (number of juveniles per female) and body length $(\mathrm{mm})$ (average $+\mathrm{SD}$ ) of acclimated Daphnia longispina from reference (Ref1 and Ref2) and historically stressed (Cont1 and Cont2) populations exposed to ASTM hardwater (white bars), $15 \mu \mathrm{g} / \mathrm{L}$ copper (heavy grey bars), $30 \mu \mathrm{g} / \mathrm{L}$ copper (medium grey bars) and $60 \mu \mathrm{g} / \mathrm{L}$ copper (light grey bars). Coefficients of variation ( $\%)$ are presented. *Significant difference $(p \leqslant 0.05$ ) relative to the respective control (ASTM hardwater).

and Cont2 (Miller and Feltz tests: $P<0.005, \chi^{2}(2)=$ 16.8 and 11.7 , respectively).

\section{Discussion}

The quantification of differences in sensitivity to chemical stress among populations living in reference and historically impacted sites was the first goal of this work. Not surprisingly the results obtained by exposing nonacclimated populations to very and moderately toxic water samples showed that individuals from contaminated populations exhibited higher tolerance to lethal levels of contamination than those from reference sites. Similar results were found with other species and other contaminants (Brown, 1978; LeBlanc, 1982; France, 1987; Blanck et al., 1988; Bodar et al., 1990; Holloway et al., 1990; Münzinger and Monicelli, 1992; Stuhlbacher and Maltby, 1992; Donker et al., 1993; Stuhlbacher et al., 1993; Taylor and Feyereisen, 1996; Devars et al., 1998; Pereira et al., 1999; Spurgeon and Hopkin, 2000). More interestingly, comparison of results for nonacclimated individuals exposed to lethal (V1) and sublethal (T7) levels of contamination indicated that, although individuals from contaminated populations were less prone to mortality when exposed to contaminated samples than reference populations, all four populations exhibited similar reproductive outputs in moderately toxic waters. A similar result was obtained by Stuhlbacher and Maltby (1992) with the amphipod Gammarus pulex pre-exposed to cadmium and zinc, which exhibited an increased tolerance to lethal levels of those toxicants, but showed similar sensitivity in sublethal assays relative to unstressed individuals.

A second objective was to determine if tolerance differences between historically stressed and reference populations were due only to acclimation or significant alterations in the gene pool of stressed populations had occurred. Here, a lower sensitivity of populations Cont 1 and Cont 2 to very toxic waters (samples V1 to V2) was observed, both with nonacclimated (Fig. 2; sample V1) and with acclimated (Fig. 4; samples V4, V3, and V2) individuals. This strongly supports the existence of a genetic basis for the observed differences in sensitivity to lethal levels of stress, as these persisted after controlling for maternal and environmental influences through acclimatization (Klerks and Weis, 1987; Lam, 1999). Differences in sublethal endpoints, among stressed and reference populations exposed to moderately toxic waters, were less evident. Though relevant information 
on coefficients of variation was gathered, similar reproductive outputs in all four populations were observed after exposure to samples T7 to T5 (Figs. 3 and 5). Further supporting evidence for genetically determined differences in resistance to sublethal levels of metal contamination was obtained when individuals were exposed to copper solutions of $60 \mu \mathrm{g} / \mathrm{L}$ (reproduction) and 15 and $30 \mu \mathrm{g} / \mathrm{L}$ (body length), where historically stressed populations were significantly more resistant than the reference population. Although the results are consistent with the microevolutionary hypothesis, i.e., contaminated populations have evolved and thus there has been a shift in the gene pool relative to founder (reference) populations, it is not possible to conclude if this took place through the elimination of sensitive individuals (genetic erosion) or through the spread of new genes (through mutation) or new genotypes (through sexual recombination).

The comparison of resistance differences between reference and stressed populations at lethal (very toxic waters) and sublethal (moderately toxic waters) levels of contamination, which was the third main objective of this study, corroborated the convergence hypothesis, i.e., that genetically determined responses converge from lethal to sublethal toxicant exposures. Similarly to the study of D. magna clones by Barata et al. (2000), increased differences in sensitivity to lethal levels of contamination between reference and stressed populations were associated with higher toxicity, most obviously with the exposure to the V4 water sample (Fig. 4A), where stressed populations began to suffer lethal effects only after all reference individuals had perished. On exposure to V3 (Fig. 4B) (less toxic than V4), there occurred a clear time overlap of lethal responses among reference and contaminated populations: almost $20 \%$ of mortality in stressed populations was already recorded when the most resistant reference individuals died. A much more intense overlap occurred with an even less toxic water sample (Fig. 4C, sample V2). As previously explained, resistance differences between populations were even less intense at sublethal levels of exposure (Figs. 6 and 7), which also corroborated the convergence hypothesis.

Many workers have reported a loss of genetic variability in resistant populations. Nordal et al. (1999) reported that the copper-tolerant plant Lychnis alpina (Caryophyllaceae) presented a lower genetic variability than nonresistant populations, suggesting the occurrence of founder effect processes. However, the opposite has also been observed (Bijlsma and Loeschcke, 1997). In the present work, a clear tendency in terms of either an increase or a decrease in variability was not observed, although whenever significant differences existed between the control and the contaminated water, an increase in variability was also noted. Two exceptions occurred: the reproductive output in the nonacclimated population Ref2 (Fig. 3) and body length in population Cont2 (Fig. 7), where variability decreased with increasing stress.

\section{Conclusion}

This study enlarges the examples of naturally occurring populations that have developed tolerance to contaminants following long-term exposures (i.e., decades). It goes further by providing evidence for the existence of genetically determined resistance; i.e., if the stress disappears the populations maintain resistance to that specific contaminant. This is important information when planning risk assessment studies where natural populations can be used to perform toxicity assays, as they can remain resistant to specific contaminants from past exposure events.

\section{Acknowledgment}

This work was partially funded by Fundação para a Ciência e a Tecnologia (Portugal)—PRAXIS XXI.

\section{References}

Allen, Y., Calow, P., Baird, D.J., 1995. A mechanistic model of contamination-induced feeding inhibition in Daphnia magna. Environ. Toxicol. Chem. 14, 1625-1630.

American Society of Testing and Materials (ASTM), 2000. Standard guide for conducting acute toxicity tests on test materials with fishes, macroinvertebrates and amphibians (E729-96). In: Annual Book of American Society of Testing and Materials Standards, ASTM, Philadelphia, vol. 11.05, pp. 213-223.

Baird, D.J., Soares, A.M.V.M., Girling, A., Barber, M.C., Calow, P., 1989. The long term maintenance of Daphnia magna Straus for use in ecotoxicity tests: problems and prospects. In: Lokke, H., Tyle, H., Bro-Rasmussen, F. (Eds.), Proceedings of the First European Conference on Ecotoxicology. Lyngby, Denmark, pp. 144-148.

Baird, D.J., Barber, I., Calow, P., 1990a. Clonal variation in general responses of Daphnia magna Straus to toxic stress: I. Chronic lifehistory effects. Funct. Ecol. 4, 399-407.

Baird, D.J., Barber, I., Calow, P., 1990b. Clonal variation in general responses of Daphnia magna Straus to toxic effects: II. Physiological effects. Funct. Ecol. 4, 409-414.

Baird, D.J., Barber, I., Bradley, M., Soares, A.M.V.M., Calow, P., 1991. A comparative study of genotype sensitivity to acute toxic stress using clones of Daphnia magna Straus. Ecotoxicol. Environ. Saf. 21, 257-265.

Barata, C., Baird, D.J., Minarro, A., Soares, A.M.V.M., 2000. Do genotype responses always converge from lethal to non-lethal toxicant exposure levels? Environ. Toxicol. Chem. 19, 2314-2322.

Bijlsma, R., Loeschcke, V., 1997. Environmental Stress. Adaptation and Evolution. Biekhäuser-Verlag, Basel.

Blanck, H., Wangberg, S.-A., Molander, S., 1988. Pollution-induced community tolerance: a new ecotoxicological tool. In: Cairns, J., Pratt, J.R. (Eds.), Functional Testing of Aquatic Biota for Estimating Hazard of Chemicals. ASTM STP988, ASTM, Philadelphia. 
Bodar, C.W.M., van der Sluis, I., van Montfort, J.C.P., Voogt, P.A., Zandee, D.I., 1990. Cadmium resistance in Daphnia magna. Aquat. Toxicol. 16, 33-40.

Bradley, M.C., Baird, D.J., Calow, P., 1991. Mechanisms of energy allocation to reproduction in the cladoceran Daphnia magna Straus. Biol. J. Linn. Soc. 44, 325-333.

Brown, B.E., 1978. Lead detoxification by a copper-tolerant isopod. Nature 276, 388-390.

Devars, S., Hernández, R., Moreno-Sánchez, R., 1998. Enhanced heavy metal tolerance in two strains of photosynthetic Euglena gracilis by preexposure to mercury or cadmium. Arch. Environ. Contam. Toxicol. 34, 128-135.

Donker, M.H., Zonneveld, C., van Straalen, N.M., 1993. Early reproduction and increased reproductive allocation in metaladapted populations of the terrestrial isopod Porcellio scaber. Oecologia 96, 316-323.

Forbes, V.E., Moller, V., Depledge, M.H., 1995. Intrapopulation variability in sublethal response to heavy metal stress in sexual and asexual gastropod populations. Funct. Ecol. 9, 477-484.

France, R.L., 1987. Differences in H-ion sensitivity among Hyalella azteca populations: an illustrative hypothesis invoking natural selection. Ann. Soc. R. Zool. Belg. 117, 129-138.

Groenendijk, D., Kraak, M.H.S., Admiraal, W., 1999. Efficient shedding of accumulated metals during metamorphosis in metaladapted populations of the midge Chironomus riparius. Environ. Toxicol. Chem. 18, 1225-1231.

Grothe, D.R., Kimerle, R.A., 1985. Inter- and intra-laboratory variability in Daphnia magna effluent toxicity results. Environ. Toxicol. Chem. 4, 189-192.

Holloway, G.J., Sibly, R.M., Povey, S.R., 1990. Evolution in toxinstressed environments. Funct. Ecol. 4, 289-294.

Honor, S.G., Hilt, B.A., 1985. Distribution of zinc tolerance bacteria in stream sediment. 128, 155-160.

Howell, R., 1985. Effect of zinc and cadmium toxicity to the amphipod Gammarus pulex. Hydrobiologia 123, 245-249.

Klerks, P.L., Weis, J.S., 1987. Genetic adaptation to heavy metals in aquatic organisms: a review. Environ. Pollut. 45, 173-205.

Kuwabara, J.S., Leland, H.V., 1986. Adaptation of Selenastrum capricornutum (Chlorophyceae) to copper. Environ. Toxicol. Chem. 5, 197-203.

Lam, P.K.S., 1996. Inter-population differences in acute responses of Brotia hainanensis (Gastropoda, Prosobranchia) to cadmium: genetic or environmental variance? Environ. Pollut. 94, 1-7.

Lam, P.K.S., 1999. Methods for distinguishing genetic and environmental variance in stress tolerance. Ecol. Appl. 9, 445-449.

Lam, P.K.S., Calow, P., 1989. Intraspecific life-history variation in Lymnaea peregra (Gastropoda, Pulmonata): II. Environmental or genetical variance? J. Anim. Ecol. 58, 589-602.

LeBlanc, G.A., 1982. Laboratory investigation into the development of resistance of Daphnia magna (Straus) to environmental pollutants. Environ. Pollut. Ser. A 27, 309-322.

Lopes, I., Gonçalves, F., Soares, A.M.V.M., Ribeiro, R., 1999a. Discriminating the ecotoxicity due to metals and to low $\mathrm{pH}$ in acid mine drainage. Environ. Ecotoxicol. Saf. 44, 207-214.

Lopes, I., Gonçalves, F., Soares, A.M.V.M., Ribeiro, R., 1999b. Ecotoxicological tools in the remediation of acid mine drainage. Toxicol. Environ. Chem. 70, 441-460.

Lopes, I., Gonçalves, F., Soares, A.M.V.M., Ribeiro, R., 2000. Field validation of specific ecotoxicological tools for aquatic systems impacted with acid mine drainage. Int. J. Environ. Stud. 58, 3-20.

Lucan-Bouché, M.-L., Biagianti-Risbourg, S., Arsac, F., Vernet, G., 1999. An original decontamination process developed by the aquatic oligochaete Tubifex tubifex exposed to copper and lead. Aquat. Toxicol. 45, 9-17.

Maltby, L., Crane, M., 1994. Responses of Gammarus pulex (Amphipoda, Crustacea) to metalliferous effluents: identification of toxic components and the importance of interpopulation variation. Environ. Pollut. 84, 45-52.

Maltby, L., Calow, P., Cosgrove, M., Pindar, L., 1987. Adaptation to acidification in aquatic invertebrates: speculation and preliminary observations. Ann. Soc. R. Zool. Belg. 117, 105-114.

Münzinger, A., Monicelli, F., 1992. Heavy metal and co-tolerance in a chromium tolerant strain of Daphnia magna. Aquat. Toxicol. 23, 203-216.

Nies, D.H., Silver, S., 1995. Ion efflux systems involved in bacterial metal resistances. J. Ind. Microbiol. 14, 186-199.

Nordal, I., Haraldsen, K.B., Ergon, ̊., Eriksen, A.B., 1999. Copper resistance and genetic diversity in Lychnis alpina (Caryophyllaceae) populations on mining sites. Fol. Geobot. 34, 471-481.

Pereira, E.G., Moura, I., Costa, J.R., Mahony, J.D., Thomann, R.V., 1995. The S. Domingos mine: a study of heavy metals contamination in the water column and sediments of the Chança river basin by discharge from and ancient cupriferous pyrite mine (Portugal). Mar. Freshwater Res. 46, 145-151.

Pereira, A.M.M., Soares, A.M.V.M., Gonçalves, F., Ribeiro, R., 1999. Test chambers and test procedures for in situ toxicity testing with zooplankton. Environ. Toxicol. Chem. 18, 1956-1964.

Pereira, A.M.M., Soares, A.M.V.M., Gonçalves, F., Ribeiro, R., 2000. Laboratory versus in situ chronic toxicity testing with dafnids. Environ. Ecotoxicol. Saf. 47, 27-38.

Pickaver, A.H., Lyes, M.C., 1981. Aerobic microbial activity in surface sediments containing high or low concentrations of zinc taken from Dublin Bay, Ireland. Estuar. Coast. Shelf Sci. 12, 13-22.

Posthuma, L., van Straalen, N.M., 1993. Heavy metal adaptation in terrestrial invertebrates: a review of occurrence, genetics, physiology and ecological consequences. Comp. Biochem. Physiol. 106, $11-38$.

Pyke, D.A., Thompson, J.N., 1986. Statistical analysis of survival and removal rate experiments. Ecology 67, 240-245.

Reinikainen, M., Hietala, J., Walls, M., 1998. Adaptations and resistance of zooplankton to stress: effects of genetic, environmental, and physiological factors. Ecotoxicol. Environ. Saf. 40, $77-80$.

Ribeiro, R., Martins, A.M.A., Correia, J.C.A., Lopes, I., Pereira, A., Canteiro, M.H.S.F., Gonçalves, F., Soares, A.M.V.M., 1995. Vertebrados da zona de S. Domingos (Baixo Alentejo). Cienc. Biol. Ecol. Syst. 15, 33-47.

Ribeiro, R., Lopes, I., Pereira, A.M.M., Gonçalves, F., Soares, A.M.V.M., 2000. Survival time of Ceriodaphnia dubia in acid waters with metal contamination. Bull Environ. Contam. Toxicol. 64, 130-136.

Soares, A.M.V.M., Baird, D.J., Calow, P., 1992. Interclonal variation in the performance of Daphnia magna Straus in chronic bioassays. Environ. Toxicol. Chem. 11, 1477-1483.

Sparks, T., 2000. Statistics in Ecotoxicology. Wiley, West Sussex.

Spurgeon, D.J., Hopkin, S.P., 2000. The development of genetically inherited resistance to zinc in laboratory-selected generations of the earthworm Eisenia fetida. Environ. Pollut. 109, 193-201.

Stuhlbacher, A., Maltby, L., 1992. Cadmium resistance in Gammarus pulex (L.). Arch. Environ. Contam. Toxicol. 22, 319-324.

Stuhlbacher, A., Bradley, M.C., Naylor, C., Calow, P., 1993. Variation in the development of cadmium resistance in Daphnia magna Straus: effect of temperature, nutrition, age and genotype. Environ. Pollut. 80, 153-158.

Taylor, M., Feyereisen, R., 1996. Molecular biology and evolution of resistance to toxicants. Mol. Biol. Evol. 13, 719-734.

Weber, C.I., 1991. Methods for measuring the acute toxicity of effluents to freshwater and marine organisms. EPA/600/4-90/027. U.S. Environmental Protection Agency, Cincinnati, OH.

Zar, J.H., 1996. Biostatistical Analysis. Prentice-Hall, Englewood Cliffs, NJ. 